\title{
Examining physics identity development through two high school interventions
}

\author{
Hemeng Cheng ${ }^{1,2}$, Geoff Potvin ${ }^{1,2}$, Raina Khatri ${ }^{2}$, Laird Kramer ${ }^{1,2}$, Robynne M. Lock ${ }^{4}$, and Zahra Hazari ${ }^{1,2,3}$ \\ ${ }^{1}$ Department of Physics, Florida International University, 11200 SW $8^{\text {th }}$ St, Miami, FL 33199 \\ ${ }^{2}$ STEM Transformation Institute, Florida International University, $11200 \mathrm{SW} 8^{\text {th }}$ St, Miami, FL 33199 \\ ${ }^{3}$ Department of Teaching \& Learning, Florida International University, 11200 SW ${ }^{\text {th }}$ St, Miami, FL 33199 \\ ${ }^{4}$ Department of Physics \& Astronomy, Texas A\&M University-Commerce, Commerce, TX 75429
}

\begin{abstract}
As part of the STEP UP 4 Women project, a national initiative to empower high school teachers to recruit women to pursue physics degrees in college, we developed two lessons for high school physics classes that are intended to facilitate the physics identity development of female students. One discusses physics careers and links to students' own values and goals; the other focuses on a discussion of underrepresentation of women in physics with the intention of having students elicit and examine stereotypes in physics. In piloting these lessons, we found statistically significant improvements in students' identities, particularly recognition beliefs (feeling recognized by others as a physics person) and beliefs in a future physics career. Moreover, female students have larger gains than male students in future beliefs (seeing themselves as physicists in the future) from both lessons, which makes it promising to contribute to alleviating the underrepresentation of women in physics. Using structural equation modeling, we test a path model of various physics identity constructs, extending an earlier, established model. In this paper, we also compare a preliminary structural analysis of students' physics identities before and after the career lesson, with an eye towards understanding how students' identities develop over time and due to these experiences.
\end{abstract}

\section{INTRODUCTION}

Compared with biology, chemistry and several other sciences, the participation of women in physics has remained remarkably low for nearly two decades (with around 19\% bachelor's degrees awarded to women in 2015) [1]. This long-standing issue has taken on a new urgency in light of the steady trend of increasing physics majors overall while women's representation has stagnated. However, given the number of physics undergraduates, college retention rates and the number of physics teachers in high schools across the US, if about half of high school physics teachers recruited a single additional female student per year, parity in representation would be achieved amongst college physics majors.

One avenue to potentially address this issue is through efforts to improve students' physics identity, which has been found to be strongly related to students' engagement and persistence in physics $[2,3]$ and to significantly predict students' physics-related career choices [2, 4]. Prior work has developed and tested this theoretical framework, which posits three underlying sub-constructs that moderate physics identity development: recognition beliefs, interest (desire/curiosity to think about and understand physics), and performance/competence beliefs (beliefs in one's ability to perform required physics tasks/understand physics content) [2-4]. Research using this theoretical framework has further revealed valid and reliable survey measures for all of these constructs $[4,5]$.

Moreover, prior research has revealed that high school physics teachers are positioned to attract students to physicsrelated careers, including students who were not previously interested in physics. Surveys of more than 900 female physics undergraduates showed that female students are attracted to physics (from other career interests) during high school at more than double the rates than during middle school or college [6]. In addition, both male and female teachers have been found to be equally effective in attracting female students to science, including physics [7].

This paper reports on data collected during the first year of the STEP UP 4 Women project, a national initiative to empower high school teachers to recruit women to pursue physics degrees in college. Our goal is to test the effect of research-based approaches on female students' physics identity. The research questions addressed in this paper are:

- What is the effect of research-based interventions on high school students' physics identity and future intentions for a physics career?

- Is the effect different for female students than that observed for male students?

- How do utility value (seeing physics as having value in one's future) and the identity subconstructs (from which the interventions were developed) affect physics identity and future intentions for a physics career?

\section{METHODOLOGY}

Research-Based Approaches: The treatments implemented by the teachers who participated in this study include: (a) ongoing general classroom strategies that center on recognizing female students and (b) two classroom interventions that focus on: i) discussing underrepresentation and ii) exposing students to careers in physics and matching personal values to physics careers. To explain briefly, the general strategies (a) can be implemented throughout the year and take the form, for example, of efforts such as scaffolding challenges to students by providing multiple resources and through verbal reinforcement/encouragement, appreciating different types of individual success, allowing 
TABLE 1. Confirmatory factor analysis estimates for physics identity

\begin{tabular}{|c|c|c|c|c|c|c|}
\hline $\begin{array}{l}\text { Latent } \\
\text { Variable }\end{array}$ & Indicator variable & $\begin{array}{l}\text { Standard } \\
\text { factor } \\
\text { loading }\end{array}$ & $\begin{array}{l}\text { Standard } \\
\text { error }\end{array}$ & $\begin{array}{l}\text { Item } \\
\text { reliabili } \\
\text { ty }\left(R^{2}\right)\end{array}$ & $\begin{array}{l}\text { Construct } \\
\text { reliability }\end{array}$ & $\begin{array}{l}\text { Average } \\
\text { Variance } \\
\text { Extracted }\end{array}$ \\
\hline Identity & Q1a: I see myself as a physics person & 1.000 & 0.079 & 1.000 & 1 & 1 \\
\hline \multirow[t]{4}{*}{ Recognition } & Q1b: My physics teacher sees me a physics person & 0.727 & 0.093 & 0.528 & \multirow{4}{*}{0.882} & \multirow[t]{4}{*}{0.654} \\
\hline & Q1c: My family sees me a physics person & 0.869 & 0.093 & 0.755 & & \\
\hline & Q1d: My friends/classmates see me a physics person & 0.905 & 0.088 & 0.819 & & \\
\hline & Q1e: Others ask for my advice/input in physics & 0.716 & 0.101 & 0.512 & & \\
\hline \multirow[t]{4}{*}{ Future } & Q1p: I can see myself as a physicist & 0.902 & 0.091 & 0.814 & \multirow[t]{4}{*}{0.800} & \multirow[t]{4}{*}{0.859} \\
\hline & Q1q: A future in physics is a possibility for me & 0.958 & 0.091 & 0.918 & & \\
\hline & $\begin{array}{l}\text { Q1r: I am likely to major in physics in } \\
\text { college/university }\end{array}$ & 0.931 & 0.087 & 0.866 & & \\
\hline & $\begin{array}{l}\text { Q1s: I could see myself pursuing a physics-related } \\
\text { career }\end{array}$ & 0.915 & 0.098 & 0.837 & & \\
\hline \multirow[t]{4}{*}{ Interest } & Q11: I am interested in learning more about physics & 0.915 & 0.085 & 0.838 & \multirow[t]{4}{*}{0.800} & \multirow[t]{4}{*}{0.877} \\
\hline & Q1m: Topics in physics excites my curiosity & 0.932 & 0.083 & 0.869 & & \\
\hline & Q1n: I enjoy learning about physics & 0.971 & 0.080 & 0.944 & & \\
\hline & Q1o: Physics is fun for me & 0.927 & 0.085 & 0.859 & & \\
\hline \multirow{6}{*}{$\begin{array}{l}\text { Performancel } \\
\text { competence }\end{array}$} & Q1f: I am confident that I can understand physics & 0.888 & 0.083 & 0.788 & \multirow[t]{6}{*}{0.857} & \multirow[t]{6}{*}{0.772} \\
\hline & Q1g: I can do well on exams in physics & 0.842 & 0.082 & 0.710 & & \\
\hline & Q1h: I understand concepts I have studied in physics & 0.899 & 0.076 & 0.808 & & \\
\hline & Q1i: Learning physics is comfortable for me & 0.917 & 0.083 & 0.840 & & \\
\hline & Q1j: I feel comfortable solving physics problems & 0.920 & 0.078 & 0.846 & & \\
\hline & Q1k: I can overcome setbacks in physics & 0.801 & 0.080 & 0.641 & & \\
\hline \multirow[t]{3}{*}{ Utility } & $\begin{array}{l}\text { Q1t: The skills I learn in physics will be useful for } \\
\text { my future }\end{array}$ & 0.930 & 0.088 & 0.864 & \multirow[t]{3}{*}{0.750} & \multirow[t]{3}{*}{0.824} \\
\hline & $\begin{array}{l}\text { Q1u: Studying physics gives me a clear advantage in } \\
\text { the future }\end{array}$ & 0.903 & 0.092 & 0.816 & & \\
\hline & $\begin{array}{l}\text { Q1v: Learning physics will be beneficial for my } \\
\text { career }\end{array}$ & 0.890 & 0.101 & 0.791 & & \\
\hline
\end{tabular}

second chances to reduce anxiety and to focus on mastery, acknowledging successes publicly, directing others to female students for help, etc. These strategies are based on prior research in these domains $[2,8]$.

The lesson on the discussion of underrepresentation/equity is designed to reveal unconscious biases and help female students counter stereotypes and neutralize the effect of such biases through engaging in discussions about previous barriers faced by women, the current state of women in physics across the world, and the role of culture and unconscious bias in the gendering of physics. The discussion of underrepresentation has been found to positively affect the physics identity development of female students with no significant effect on male students $[2,3,9,10]$.

The second lesson is focused on values affirmation and a physics career exploration designed to elicit students' personal values/career goals and how they might be achieved through a physics career, with an eye especially to communal goals such as helping and working with others. A focus on values affirmation has been found to reduce the gender achievement gap and endorsement of the stereotype that men do better than women in physics [11-14].

Data collection: There were 10 master teachers and approximately 823 students who participated from 9 different high schools (in 8 states) across the US. Most students were taking their first high school physics course, for some an AP physics course, with 312 identifying themselves as female and 511 as male. As teachers implemented the general strategies and two classroom lessons, 4 rounds of survey were administered to measure students' physics identity (before and after each lesson, staggered during Fall 2017). Some teachers left longer gaps of time between the lessons, which is an uncontrolled source of variance in the current analysis. The specific items appear in the second column of TABLE 1; each item was measured on a uniform 11-point anchored scale. The items were drawn from prior work on physics identity [4] and were augmented with items measuring two more constructs: utility value and the "future" construct $[2,15]$.

Methods of analysis: The analysis consisted of three parts. First, Confirmatory Factor Analysis (CFA) assessed how well the items measure the latent variables, as summarized in TABLE 1. The correspondence between measured indicators and latent variables and the factor loadings, as well as the fit indices of the measurement model and convergent validity are shown in TABLE 1 . Here we use Q1a ("I see myself as a physics person") to refer to overall physics identity. Second, we assessed how each construct changed before and after each lesson, as well as between the lessons. This information is summarized in TABLE 2, with significant changes (according to paired t-tests) indicated. Thirdly, the proposed physics identity development model was tested using structural equation modeling (SEM) [16] (see FIG 1). This analysis was repeated for the first two rounds of data collected. 
TABLE 2. Identity development through two class interventions

\begin{tabular}{|c|c|c|c|c|c|c|}
\hline \multirow[b]{2}{*}{ Factor } & \multicolumn{3}{|c|}{ All students } & \multicolumn{3}{|l|}{ Female only } \\
\hline & $\begin{array}{l}\text { Career } \\
\text { Lesson }\end{array}$ & $\begin{array}{l}\text { Representation } \\
\text { Lesson }\end{array}$ & $\begin{array}{l}\text { Combined } \\
\text { (including gap) }\end{array}$ & Career Lesson & $\begin{array}{l}\text { Representation } \\
\text { Lesson }\end{array}$ & $\begin{array}{l}\text { Combined } \\
\text { (including gap) }\end{array}$ \\
\hline Recognition & $+1.77 * *$ & $+2.77 * * *$ & $+4.38 * * *$ & $+0.73(\mathrm{~ns})$ & $+2.67 * *$ & $+5.04 * * *$ \\
\hline Future & $+6.80 * * *$ & $+2.92 * * *$ & $+6.11 * * *$ & $+7.56 * * *$ & $+4.55 * * *$ & $+8.36 * * *$ \\
\hline Interest & $-2.20 * *$ & $-1.47 *$ & $-3.70 * * *$ & $-3.18 * *$ & $-2.18 *$ & $-3.50 *$ \\
\hline Performance/Competence & $-0.83(\mathrm{~ns})$ & $-0.32(\mathrm{~ns})$ & $-2.52 * *$ & $-1.06(\mathrm{~ns})$ & $+0.07(\mathrm{~ns})$ & $-1.63(\mathrm{~ns})$ \\
\hline Utility Value & $5.30 * * *$ & $-1.41(\mathrm{~ns})$ & $-0.04(\mathrm{~ns})$ & $+6.17 * * *$ & $-1.26(\mathrm{~ns})$ & $+1.93(\mathrm{~ns})$ \\
\hline
\end{tabular}

\section{RESULTS}

\section{A. Identity development}

For both lessons, there were significant changes in students' identities, especially with respect to recognition and future beliefs. The biggest gain observed were for the future beliefs construct $-6.8 \%$ and $2.9 \%$ across career and representation lessons respectively, and a total of $6.1 \%$ through the entire study time period in Fall 2017 ( $p<0.001)$. The fact that the combined effect is smaller than the change across the career lesson is because of a decline during the gap between lessons. The two interventions and general strategies also improved students' recognition beliefs, where the representation lesson had a larger effect than the career lesson, and there was almost no change in the gap. However, students' interest in physics, confidence about their performance/competence in physics decreased during the lessons and across the whole semester. This is consistent with other work that has found these constructs decline during a physics course [17]. The two lessons did not ameliorate these declines, despite gains in recognition and future beliefs. Although the change in overall utility value is not significant, there is a significant gain across the career lesson.

There are also different effects for female students in these lessons. From TABLE 2, note that female students not only have bigger gains in recognition beliefs, future beliefs and utility value, but also have a smaller loss in interest and no statistically significant decrease in performance/competence over the semester, in contrast to the male students. Although our two lessons help both male and female students increase their recognition and future beliefs, female students gain more in their future beliefs through both lessons than male students, which slightly narrows the gap between male and female students at the end of the semester compared with initially (note that male students do have higher responses to these constructs overall). In terms of recognition beliefs, although female students gain less from the career lesson, the increase due to the underrepresentation lesson is almost the same. In sum, these results affirm that students' physics identities can be impacted by exposure to physics careers and their social impact, as well as engaging in discussion of the current condition of women in physics, unconscious bias effects, and core equity issues.

\section{B. Path models of identity}

FIG.1 shows the best fit structural equation model drawing on prior theory and using our data. The overall fit indices for the measurement model are GFI of 0.940, AGFI of 0.917, RMSEA of 0.073 , SRMR of 0.066 and NNFI of 0.952. All of these fit indices indicate that the measurement variables accurately reflect the latent variables. As established repeatedly in prior work, recognition and interest mediate the effect of performance/competence on identity [4, 5] as well as future beliefs. Interest mediates the effect of utility on identity and future beliefs. All of the standardized path estimates are significant $(p<0.001)$ for Round 1 data.

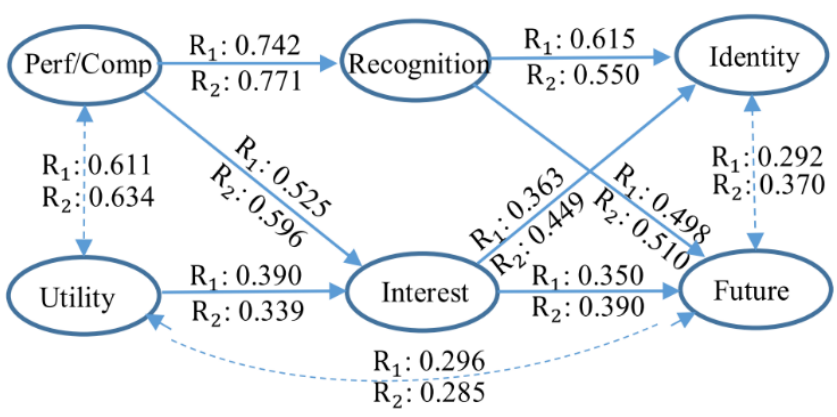

FIG 1. Diagram of proposed structural model for the structural equation modeling analysis

A significant direct path from utility value to interest was found. This finding indicates that when students realize physics is useful for their future goals, they may become more interested in physics. This is consistent with other work, for example, Phalet et al found that by fostering positive instrumentality, educators may be able to enhance students' intrinsic motivation in academic contexts [18]. Additionally, performance/competence beliefs and utility value are significantly related to each other, which indicates that if a student feels competent and able to perform well in physics, they tend to attach more value to school work. In return, if a person knows that the physics content they are learning is helpful for their goals and career, they may improve in their performance/competence beliefs. Again, this is consistent 
with several other findings $[15,19,20]$.

Like identity, future beliefs is predicted by recognition beliefs and interest. It is not hard to understand that when students are interested in physics and feel recognized, they are more likely to see themselves as a physics person and want to pursue a physics career in the future. Students' future beliefs are bi-directionally related to utility value and identity. These findings are again supported by expectancy-value theory $[15,19]$.

Finally, one goal of the project is to understand how these path models change over time. As a first step in this direction, the coefficients for Round $2\left(\mathrm{R}_{2}\right)$ are also indicated in FIG 1 . The fit indices for the measurement model are: GFI of 0.927, AGFI of 0.900, RMSEA of 0.081, SRMR of 0.063 and NNFI of 0.950 . These fit indices indicate that this model has a slightly poorer fit compared with Round 1 . In future work, we will extend this to include all four rounds of data and conduct a time-series analysis to examine how the various identity constructs are associated over time.

\section{CONCLUSIONS}

In this study, we found significant changes in high school students' physics identity through two interventions. Moreover, this development impacted females differentially, with female students having gained more in their future beliefs for both lessons. For recognition beliefs, although female students gained less through the career lesson than male students, the increase due to the underrepresentation lesson was almost the same. What's more, the overall effect is larger for female students over the entire study period. These findings are important because they support the potential effectiveness of this approach to help young women feel more recognized and see themselves as a "physics person" in the present and future. Furthermore, they provide support for the STEP UP 4 Women project because they link research-to-practice by field-testing scalable educational interventions that are readily usable by teachers.

Starting from a previously validated identity model, we obtained a well-fit SEM model to explain the paths between the identity sub-constructs. We found that recognition beliefs and interest are two important and direct factors for physics identity both now and in the future, whereas performance/competence and utility value play more indirect, precursor roles.

In the future, we will modify the lessons based on the results reported here (as well as from other sources) for retesting and will collect data to compare results to classrooms that do not utilize all parts of these lessons. Further, we will extend the analyses begun here to examine in more detail how students' physics identities change over time, and due to the lessons discussed here.

\section{ACKNOWLEDGEMENTS}

The authors would like to thank the whole STEP UP 4 Women project team (www.stepup4women.org) as well as the master teachers and students who participated in the project. This material is based on work supported by the National Science Foundation under Grant No. 1721021, 1720810, 1720917, and 1720869. Any opinions expressed are those of the authors and do not necessarily reflect the views of the NSF. [1]https://www.aps.org/programs/education/statistics/wome nmajors.cfm.

[2] Z. Hazari, G. Sonnert, P. M. Sadler, and M.-C. hanahan, J. Res. Sci. Teach. 47, 978 (2010).

[3] C. Hazari, Zahra, Cass, Cheryl, Beattie, J. Res. Sci. Teach. (2015).

[4] A. Godwin, G. Potvin, Z. Hazari, and R. Lock, J. Eng. Educ. 105, 312 (2016).

[5] J. D. Cribbs, Z. Hazari, G. Sonnert, and P. M. Sadler, Child Dev. 86, 1048 (2015).

[6] Z. Hazari, E. Brewe, R. M. Goertzen, and T. Hodapp, Phys. Teach. 55, 96 (2017).

[7] G. Potvin, Z. Hazari, R. H. Tai, and P. M. Sadler, Sci. Educ. 93, 827 (2009).

[8] P. Häussler and L. Hoffmann, J. Res. Sci. Teach. 39, 870 (2002).

[9] Z. Hazari, G. Potvin, R. M. Lock, F. Lung, G. Sonnert, and P. M. Sadler, Phys. Rev. Spec. Top. - Phys. Educ. Res. 9, 020115 (2013).

[10] R. M. Lock and Z. Hazari, Phys. Rev. Phys. Educ. Res. 12, 020101 (2016).

[11] T. A. Miyake, A. Smith, L.E. Finkelstein, N. D.
Pollock, S. J. Cohen, G. L. Ito, (American Association for the Advancement of Science, 2010).

[12] G. L. Cohen, J. Garcia, N. Apfel, A. Master, and P. Brzustoski, Science. 313, 1307 (2006).

[13] G. L. Cohen, J. Garcia, V. Purdie-Vaughns, N. Apfel, P. Brzustoski, and T. A. Ito, Science. 324, 400 (2009).

[14] G. L. Walton, G. M. Cohen, N. Apfel, A. Master, and P. Brzustoski, (AAAS, 2011).

[15] A. Wigfield and J. S. Eccles, Contemp. Educ. Psychol. 25, 68 (2000)

[16] Y. Rosseel, "Package lavaan". Retrived on Apr. 24 (2018)

[17] P. Oon and R. Subramaniam, Int. J. Sci. Educ. 33, 727 (2011)

[18] K. Phalet, I. Andriessen, and W. Lens, Educ. Psychol. Rev. 16, (2004)

[19] A. Wigfield, J. S. Eccles, K. S. Yoon, R. D. Harold, A. J. A. Arbreton, C. Freedman-Doan, and P. C. Blumenfeld, J. Educ. Psychol. 89, 451 (1997).

[20] M. L. de Volder and W. Lens, J. Pers. Soc. Psychol. 42, 566 (1982) 